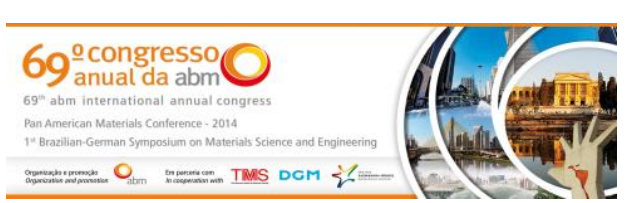

Tema: Produtos metálicos ferrososo

\title{
AUMENTO DO DESEMPENHO NO TRANSPORTE DE MINÉRIO DEVIDO A APLICAÇÃO DE AÇOS MICROLIGADOS AO NIÓBIO NA ESTRUTURA DE CAÇAMBAS DE CAMINHÕES BASCULANTES*
}

\author{
Jorge Luis Barreto ${ }^{1}$ \\ Hugo Rosa ${ }^{2}$ \\ Érico França Oliveira e Silva ${ }^{3}$ \\ Resumo \\ Marcos Alexandre Stuart Nogueira ${ }^{3}$
}

A CBMM aplicou aços microligados ao nióbio de elevada resistência mecânica em caminhões basculantes que operam nas suas instalações de Araxá, com o objetivo de reduzir o peso das caçambas e obter maior desempenho com aumento da carga transportada, redução do consumo de combustível bem como das emissões de CO2. Também tinha o objetivo de eliminar as trincas de fadiga que ocorriam sobre os chassis desses equipamentos. Os caminhões já operam há 12 meses e o objetivo desse trabalho é apresentar os resultados obtidos até o momento. Com a aplicação dos aços de elevada resistência, foi possível desenvolver um novo desenho para sua estrutura e componentes. Houve uma redução de $25 \%$ da massa da caçamba 0 que proporcionou um aumento médio de carga transportada de 40,0 t para 41,1 t ou $2,7 \%$ por viagem, trazendo até o momento, economia de 3,00\% no custo total de transporte e redução de consumo de combustível de $8,00 \%$. Não houve trincas ou deformações no sobre chassis que apoiam as caçambas.

Palavras-chave: Aços microligados; Nióbio; Emissões de $\mathrm{CO}_{2}$; Trincas de fadiga.

\section{ORE TRANSPORTATION PERFORMANCE ENHANCEMENTS ACHIEVED THROUGH THE APPLICATION OF NIOBIUM MICROALLOYED STEELS IN DUMP TRUCK BUCKETS}

\begin{abstract}
CBMM applied high strength niobium microalloyed steels in dump trucks for the company's facilities in Araxá in order to reduce bucket weight, enhance performance, decrease fuel consumption and reduce $\mathrm{CO}_{2}$ emissions. Another goal was to eliminate the fatigue cracks that typically occurred in the chassis of these vehicles. The trucks with high strength steel have now been in service for 12 months and the purpose of the current paper is to present the results obtained thus far. By using high strength steel, it was possible to develop a new design for the bucket structure and components. With the new design, there was a $25 \%$ reduction in the mass of the bucket, which has allowed for an increase in the average transported load from 40.0 tonnes per trip to 41.1 tonnes or $2,7 \%$, resulting in a savings of $3.00 \%$ in total transportation costs and a reduction of $8 \%$ in fuel consumption to date. No fatigue cracks have occurred in the chassis beams that support the buckets.
\end{abstract}

Keywords: Microalloyed Steels, Niobium, CO2 Emissions, Fatigue Cracks.

1 Departamento de Mineração, Companhia Mineradora do Pirocloro de Araxá (COMIPA), Araxá, MG, Brasil; jorgebar@cbmm.com.br.

2 Departamento de Equipamentos Moveis, Companhia Brasileira de Metalurgia e Mineração (CBMM), Araxá, MG, Brasil; hugo.rosa@cbmm.com.br.

3 Departamento de Desenvolvimento de Mercado, Companhia Brasileira de Metalurgia e Mineração (CBMM), São Paulo, SP, Brasil; erico.franca@cbmm.com.br; marcos.stuart@cbmm.com.br.

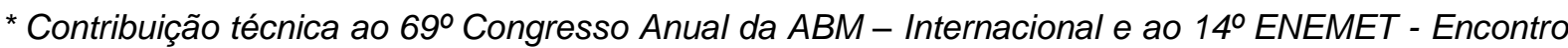
Nacional de Estudantes de Engenharia Metalúrgica, de Materiais e de Minas, 21 a 25 de julho de 2014, São Paulo, SP, Brasil.
} 


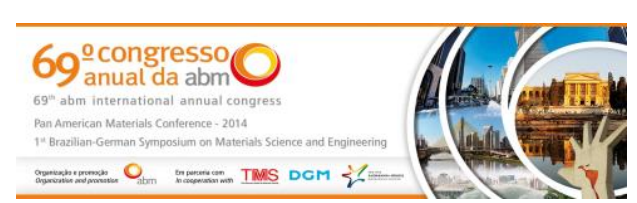

\section{INTRODUÇÃO}

\subsection{Um breve histórico}

São encontradas na literatura evidências do interesse pelo nióbio no início dos anos 20 quando foi adicionado em aços ferramenta para aumentar sua resistência ao desgaste e logo depois, em 1933, quando foi adicionado em aços inoxidáveis austeníticos, para estabilizar seus intersticiais [1,2]. No início dos anos 40, foi adicionado nas superligas de níquel para turbinas a gás, mas, até então, não era uma real opção pois as fontes desse elemento ainda não estavam plenamente desenvolvidas. Isso veio a ocorrer no início dos anos $50 \mathrm{com}$ a descoberta de reservas de pirocloro em Araxá, Triângulo Mineiro e Alto Paranaíba [3,4], Figura 1. 0 elemento ficou disponível e um intenso desenvolvimento tecnológico para sua aplicação pode ser verificado pelo número de pesquisas e de produtos que 0 utilizam.

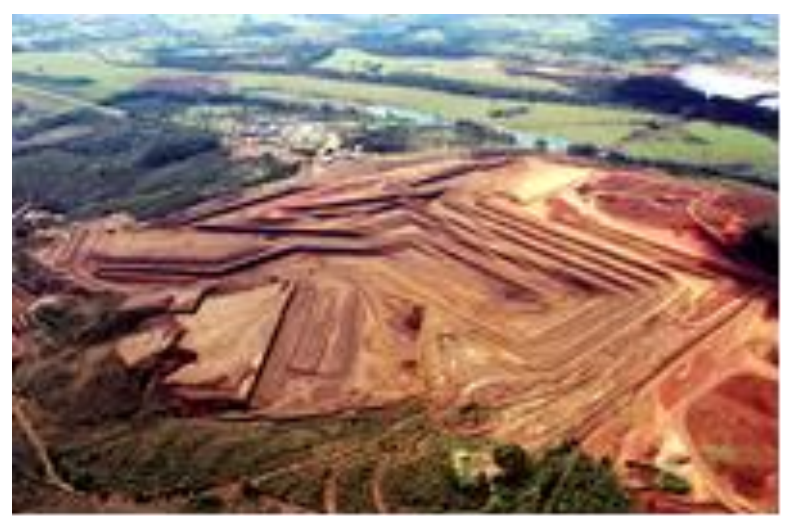

Figura 1 - Vista da mina da CBMM em Araxá

Aplicado para os mais variados segmentos de mercado, o nióbio é a base dos aços microligados de elevadas resistências mecânicas que se tornaram essenciais para viabilizar projetos de criação de infraestrutura e que otimizam o uso dos recursos naturais. Além de ser uma fornecedora de uma linha completa de produtos contendo nióbio, a CBMM desenvolve projetos com universidades, centros de pesquisa, fabricantes de aço e fabricantes de produtos de aço, sempre com o objetivo de obter um aço melhor, um aço que leve à produto de melhor desempenho. A CBMM adotou a prática de executar seus projetos de desenvolvimento, sempre que aplicável, nas suas próprias instalações da Usina de Araxá, a qual assumiu mais essa importante função de avaliar seus protótipos. O presente trabalho é exatamente um exemplo dessa iniciativa aplicada para caminhões basculantes que são utilizados para o transporte de minério e produtos gerados na sua atividade de mineração.

\subsection{Operações de Transporte nas Atividades de Mineração na CBMM e seus Caminhões Basculantes}

São transportandas por ano cerca de 12 milhões de toneladas de produtos na usina em processo já apresentado em trabalho inicial sobre esse projeto [5]. A usina tem correias transportadoras e um moderno pátio para a mistura de minério, o que minimiza a utilização de caminhões nas suas operações. A utilização intensiva de

\footnotetext{
* Contribuição técnica ao $69^{\circ}$ Congresso Anual da ABM - Internacional e ao 14ํㅡㄹ ENEMET - Encontro Nacional de Estudantes de Engenharia Metalúrgica, de Materiais e de Minas, 21 a 25 de julho de 2014, São Paulo, SP, Brasil.
} 


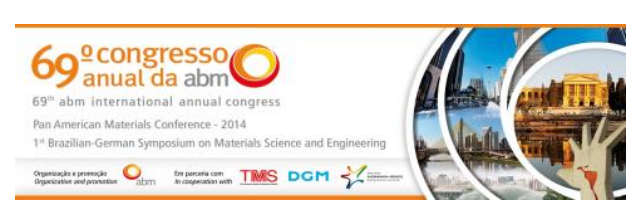

correias transportadoras é essencial para a política de sustentabilidade com a qual a Usina de Araxá é gerenciada, visando à redução contínua de emissões. Utiliza os caminhões em trechos com média de $1 \mathrm{~km}$ de distância. Conta com 13 caminhões basculantes, do tipo meia cana e que apresentam proteção interna com recobrimento com material UHMW, a fim de evitar o agarramento do minério no seu interior, Figura 2. O projeto iniciou-se com a aplicação do conceito da utilização de aços microligados ao nióbio com maiores valores de resistência mecânica do que os aços que vinham sendo utilizados nesses equipamentos. Estes eram aços carbono na estrutura e na maioria dos componentes. Com aços de maior resistência mecânica foram reduzidas as espessuras das estruturas empregadas, resultando em um equipamento mais leve e na possibilidade de aumentar a quantidade de carga transportada. Foram objetivadas reduções de consumo de combustível, com reduções de custo de transporte e menores emissões de $\mathrm{CO}_{2}$. $\mathrm{O}$ chassi sobre o qual as caçambas eram apoiadas, ou os sobre chassis, apresentavam trincas decorrentes de fadiga em serviço. Nesse caso, aplicaram-se aços de maior resistência mecânica sem reduções nas suas espessuras, com o objetivo de reduzir essas trincas que eram responsáveis por paradas para manutenção e por reduções do ciclo de vida dos caminhões.

O objetivo desse trabalho é apresentar os resultados obtidos após 12 meses de operação e mostrar as principais características dos aços utilizados que justificam as melhoras obtidas.

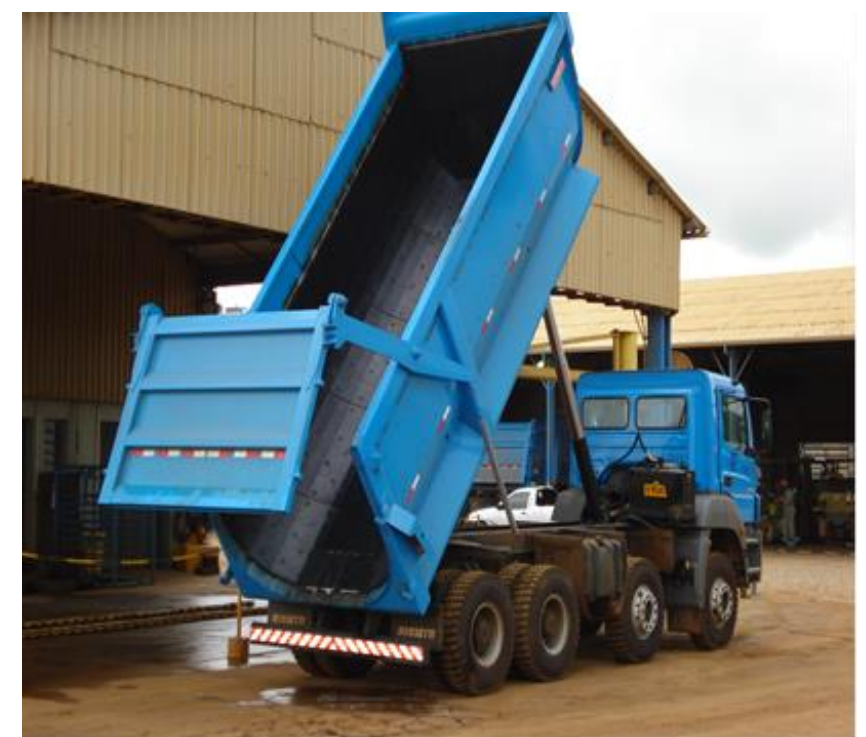

Figura 2 - Caminhão 4844 MBB - ACTROS, com caçamba meia cana de $20 \mathrm{~m}^{3}$. Presença de cobertura interior com material UHMW para evitar agarramento do minério no seu interior.

\subsection{Nióbio no Segmento Automotivo e seu Efeito para Redução de Peso}

No segmento automotivo, o nióbio vem sendo tradicionalmente utilizado nos aços microligados denominados ARBL - Alta Resistência Baixa Liga. Conforme descrito Noren e Woodhead, em trabalho publicado por Woodhead e Kewon [6], os aços microligados são: "Um aço microligado é um aço com a composição química de um aço estrutural não ligado, em muitos casos, um aço manganês ou mesmo uma aço de baixos elementos de liga, nos quais uma pequena adição de elemento de liga tem um grande efeito e às vezes um efeito marcante sobre uma ou várias das propriedades do aço". Esse conceito de aços microligados é o que torna a aplicação

\footnotetext{
* Contribuição técnica ao $69^{\circ}$ Congresso Anual da ABM - Internacional e ao 14ํㅡㄹ ENEMET - Encontro Nacional de Estudantes de Engenharia Metalúrgica, de Materiais e de Minas, 21 a 25 de julho de 2014, São Paulo, SP, Brasil.
} 
do nióbio tão especial para as estruturas metálicas como a utilizada nesses caminhões basculantes, pois todas as melhorias são decorrentes de adições inferiores a $0,10 \%$, tornando os projetos um sucesso de desempenho e de custo.

O nióbio refina os grãos austeníticos durante a laminação a quente assim como todas as fases formadas após essa operação, no resfriamento do material. Esse efeito, já bem conhecido para todos os aços ARBL, agora também está desenvolvido para quase todos os aços das famílias dos Dual Phase, Complex Phase, TRIP e Press Hardened [7-12]. O refino de grão é o único mecanismo que promove o aumento da resistência mecânica e da tenacidade ao mesmo tempo, sendo a base do conceito de redução de peso das estruturas automotivas. Com a aplicação dos aços ao nióbio ARBL de maior resistência mecânica, pode-se reduzir suas espessuras sem risco de falhas em serviço. O refino de grão leva ao refino e grande homogeneidade das microestruturas obtidas após laminação e até mesmo após tratamentos térmicos. As microestruturas finas e homogêneas vêm se mostrando a melhor forma de aumentar a capacidade dos materiais serem dobrados a frio e furados sem trincas, o que proporciona maior produtividade e menores rejeitos na produção dos componentes automotivos. Um exemplo bastante didático é ilustrado na Figura 3 onde o Dual Phase refinado pode ser dobrado sem ocorrências de trincas.

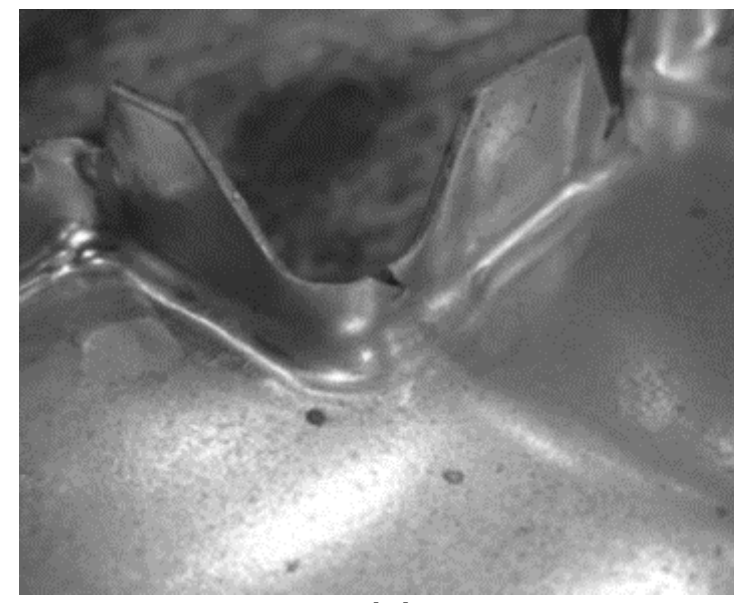

(a)

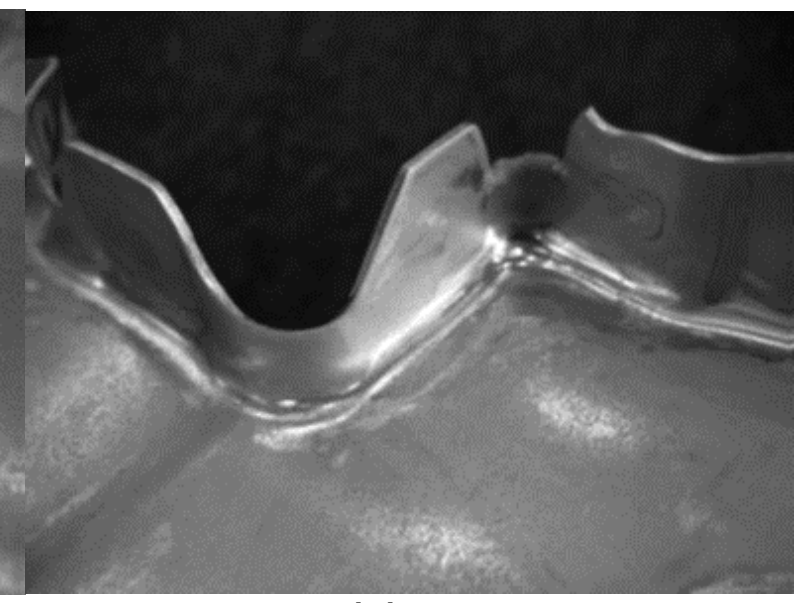

(b)

Figure 3 - Peças de aço DP 780 conformadas a frio. (a) aço convencional, (b) Aço com microestrutura homogênea e refinada [10].

\section{MATERIAIS E MÉTODOS}

\subsection{Projeto Antigo e Projeto Atual}

Durante os últimos 12 meses, foram acompanhados 7 caminhões com o conceito dos aços microligados ao nióbio dentro de uma frota de 13 caminhões. A Tabela 1 compara os materiais utilizados no projeto antigo e no projeto atual dos caminhões basculantes e as Figuras 4 e 5 mostram detalhes de alguns dos seus componentes.

\footnotetext{
* Contribuição técnica ao $69^{\circ}$ Congresso Anual da ABM - Internacional e ao 14ํㅡㄹ ENEMET - Encontro Nacional de Estudantes de Engenharia Metalúrgica, de Materiais e de Minas, 21 a 25 de julho de 2014, São Paulo, SP, Brasil.
} 


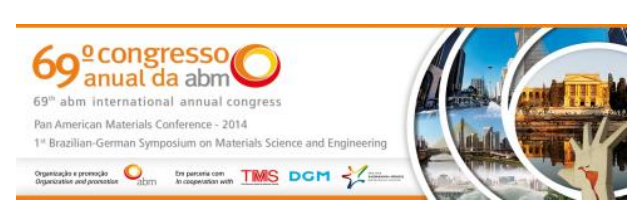

Tabela 1 - Aços utilizados nos projetos dos caminhões basculantes que operam na Usina da CBMM em Araxá

\begin{tabular}{|c|c|c|c|c|}
\hline & $\begin{array}{l}\text { Projeto } \\
\text { anterior }\end{array}$ & $\begin{array}{c}\text { Espessura da } \\
\text { chapa } \\
(\mathrm{mm})\end{array}$ & $\begin{array}{c}\text { Projeto } \\
\text { desenvolvido } \\
\text { com os aços } \\
\text { de elevada } \\
\text { resistência } \\
\text { mecânica }\end{array}$ & $\begin{array}{c}\text { Espessura da } \\
\text { chapa } \\
(\mathrm{mm})\end{array}$ \\
\hline Caminhão & $\begin{array}{c}\text { Actros } 4844 \\
\text { Modelo } 2011\end{array}$ & & $\begin{array}{c}\text { Actros } 4844 \\
\text { Modelo } 2013\end{array}$ & \\
\hline \multirow{3}{*}{ Caçamba } & Piso: S355 & 9,5 & $\begin{array}{c}\text { Piso: Hardox } \\
450\end{array}$ & 6,35 \\
\hline & $\begin{array}{l}\text { Laterais: Aço } \\
\text { carbono }\end{array}$ & 6,3 & $\begin{array}{l}\text { Laterais: } \\
\text { Hardox } 400\end{array}$ & 4,0 \\
\hline & $\begin{array}{c}\text { Estrutura: Aço } \\
\text { carbono }\end{array}$ & 8,0 a 9,5 & $\begin{array}{c}\text { Estrutura: } \\
\text { Domex 700MC }\end{array}$ & 4,75 a 8,0 \\
\hline \multirow{3}{*}{ Sobre chassis } & $\begin{array}{c}\text { Estrutura: } A c ̧ o \\
\text { carbono }\end{array}$ & $\begin{array}{c}\text { Perfis } \\
\text { longitudinais: } \\
8,0\end{array}$ & $\begin{array}{c}\text { Estrutura: } \\
\text { Domex 700MC }\end{array}$ & $\begin{array}{c}\text { Perfis } \\
\text { longitudinais: } \\
8,0\end{array}$ \\
\hline & & Reforços: 6,3 & & Reforços: 6,3 \\
\hline & & $\begin{array}{c}\text { Estrutura } \\
\text { Transversal: } \\
4,75-9,5\end{array}$ & & $\begin{array}{c}\text { Estrutura } \\
\text { transversal: } \\
4,75-9,5\end{array}$ \\
\hline \multirow{3}{*}{ Peso (kg) } & Caminhão & 11.074 & Caminhão & 11.530 \\
\hline & Caçamba & 7.426 & Caçamba & 5.470 \\
\hline & Total & 18.500 & Total & 17.000 \\
\hline
\end{tabular}

* Contribuição técnica ao 69 Congresso Anual da ABM - Internacional e ao 14ํㅡㄹ ENEMET - Encontro Nacional de Estudantes de Engenharia Metalúrgica, de Materiais e de Minas, 21 a 25 de julho de 2014, São Paulo, SP, Brasil. 

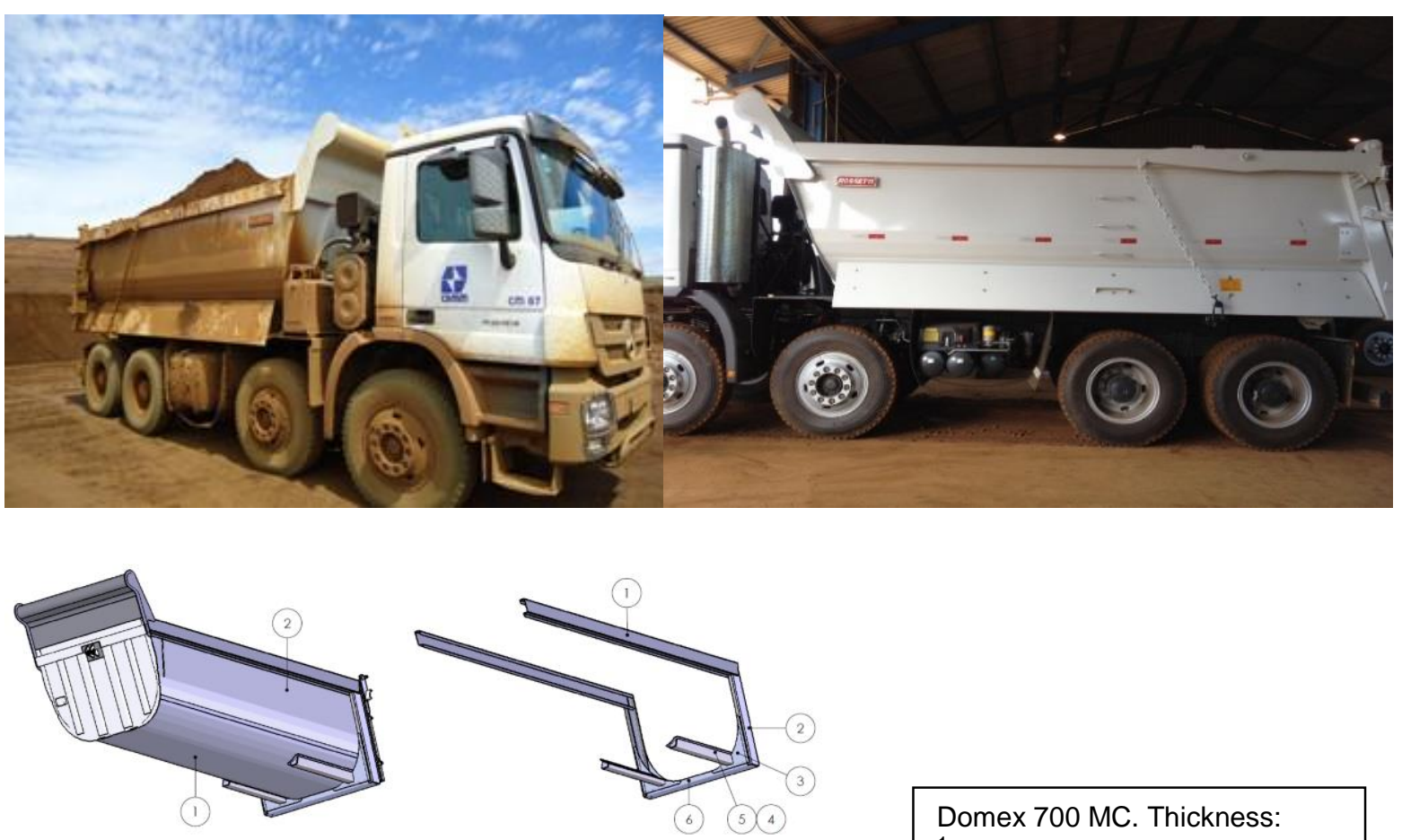

Hardox $450-$ thickness $=6,35 \mathrm{~mm}$

2 Hardox $400-$ thickness $=4,0 \mathrm{~mm}$

$$
\begin{aligned}
& \text { Domex } 700 \text { MC. Thickness: } \\
& 1 \quad 4.75 \mathrm{~mm} \\
& 2 \quad 8.00 \mathrm{~mm} \\
& 3 \quad 4.75 \mathrm{~mm} \\
& 4 \quad 6.35 \mathrm{~mm} \\
& 5 \quad 8.00 \mathrm{~mm}
\end{aligned}
$$

Figura 4 - Caçamba dos caminhões basculante em desenvolvimento na Usina da CBMM em Araxá

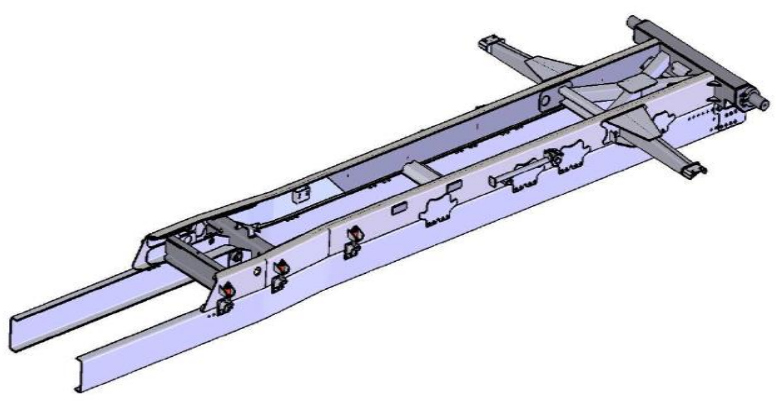

Domex $700 \mathrm{MC}$

Conic structure, reinforced arms to prevent from fatigue cracks

Figura 5- Sobre chassis dos caminhões em desenvolvimento na Usina da CBMM em Araxá

A Tabela 2 mostra as composições químicas dos aços utilizados nesses dois projetos, avaliadas segundo a Normas ASTM A751: 2008, ASTM E1086: 2008 e ASTM 415:2008. Os aços de maiores valores de resistência mecânica são micro ligados e foram fornecidos pela empresa Sueca SSAB.

\footnotetext{
* Contribuição técnica ao 69 Congresso Anual da ABM - Internacional e ao 14ํㅡㄹ ENEMET - Encontro Nacional de Estudantes de Engenharia Metalúrgica, de Materiais e de Minas, 21 a 25 de julho de 2014, São Paulo, SP, Brasil.
} 


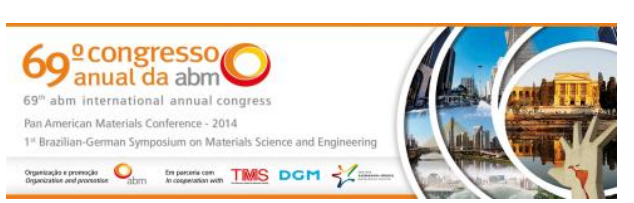

Tabela 2 - Composições químicas dos aços utilizados nos caminhões caçamba em operação na Usina da CBMM - Aço carbono estrutural padrão ASTM

\begin{tabular}{|c|c|c|c|c|c|c|c|c|c|c|}
\hline Aço & $\mathrm{C}$ & $\mathrm{Si}$ & $\mathrm{Mn}$ & $\mathrm{P}$ & $\mathrm{S}$ & $\mathrm{Cr}$ & $\mathrm{Ni}$ & $\mathrm{Mo}$ & $\mathrm{B}$ & $\mathrm{Nb}$ \\
\hline $\begin{array}{c}\text { Aço } \\
\text { Carbono }\end{array}$ & 0,25 & 0,50 & 1,70 & 0,035 & 0,035 & - & - & - & - & - \\
\hline $\begin{array}{c}\text { Hardox } \\
450\end{array}$ & 0,167 & 0,216 & 1,369 & 0,011 & 0,003 & 0,152 & 0,10 & 0,024 & 0,001 & 0,012 \\
\hline $\begin{array}{c}\text { Domex } \\
700 \mathrm{MC}\end{array}$ & 0,063 & 0,062 & 1,790 & 0,017 & 0,003 & - & - & - & $\begin{array}{c}\mathrm{V}- \\
0,011\end{array}$ & 0,056 \\
\hline
\end{tabular}

\section{RESULTADOS E DISCUSSÃO}

\subsection{Resultados}

\subsubsection{Resultados operacionais}

O caminhão Actros modelo 2013 que entrou em operação com a nova caçamba com aços microligados tinha cerca de $450 \mathrm{~kg}$ adicionais devido a dispositivos e equipamentos para controle de emissões e itens de segurança. Com a aplicação dos aços de maior resistência foi possível reduzir $1.950 \mathrm{~kg}$ da caçamba, ou seja, $25 \%$ da sua massa, o que resultou numa redução de peso total do caminhão e caçamba de $1.500 \mathrm{~kg}$. Esses $1.500 \mathrm{~kg}$ de peso a menos poderiam ser utilizados para aumento de carga transportada. Durante o período de acompanhamento foi possível aumentar a carga transportada média em $1.100 \mathrm{~kg}$ não chegando ainda ao máximo possível de aumento de carga. Com esse aumento de carga transportada, foi necessário um menor número de viagens para as mesmas quantidades transportadas, resultando numa redução no custo total de $3,0 \%$ sendo uma redução no custo de combustível de $8,0 \%$.

\subsubsection{Resistência à formação de trincas em serviço no sobre chassis}

Desde o início de operação dos novos caminhões, desde março de 2013, não houve o aparecimento de trincas ou deformações no sobre chassis. Essas ocorriam no máximo com $5.000 \mathrm{~h}$ de operação. As caçambas produzidas com aços microligados já estão operando há 6.700 h sem qualquer ocorrência. As Figuras 6 e 7 mostram essas estruturas e as diferenças de condições em serviço quanto ao aparecimento de trincas. Durante esse período não houve paradas para manutenção e correções do suporte das correntes de abertura da tampa traseira das caçambas.

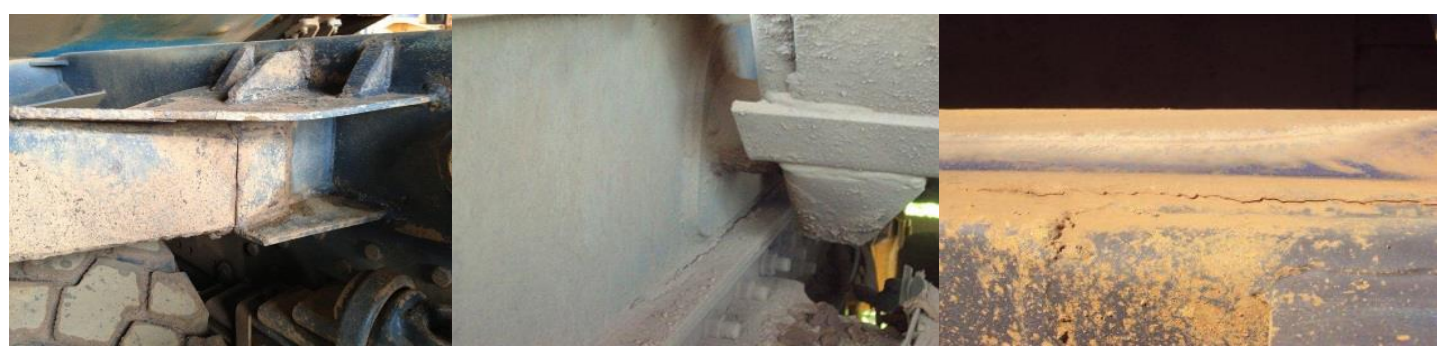

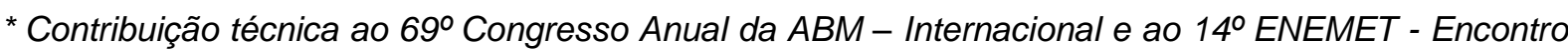
Nacional de Estudantes de Engenharia Metalúrgica, de Materiais e de Minas, 21 a 25 de julho de 2014, São Paulo, SP, Brasil.
} 


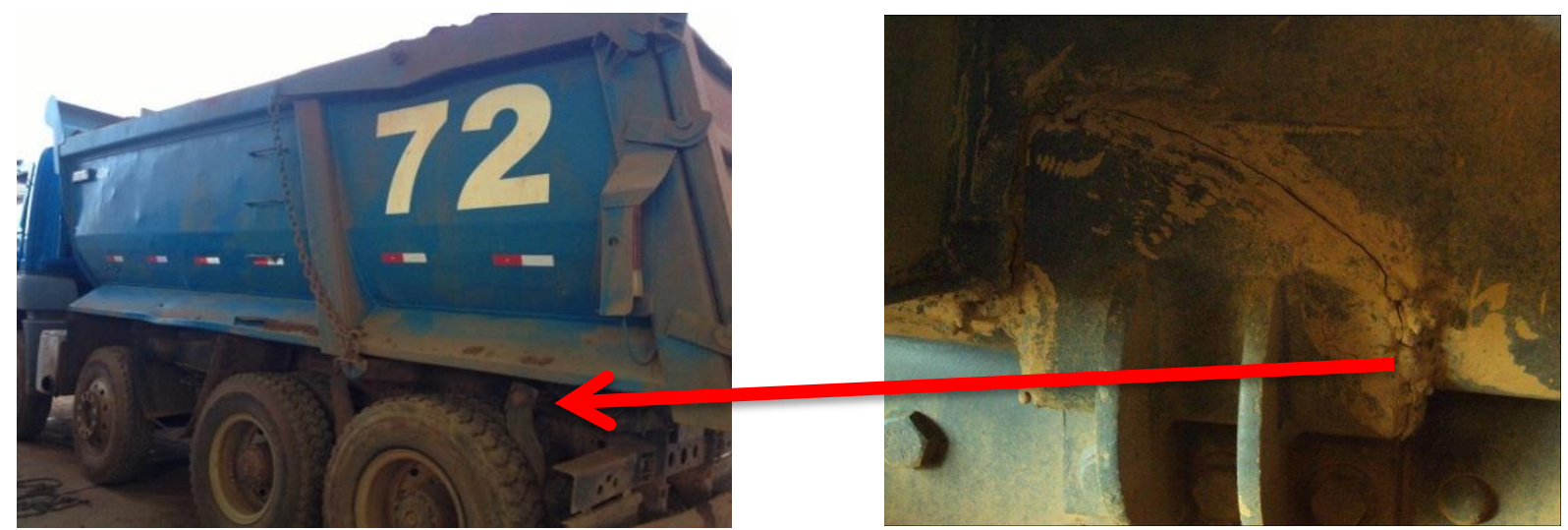

Figura 6 - Modelo anterior elaborado com aços de baixa resistência apresentando trincas de fadiga em serviço

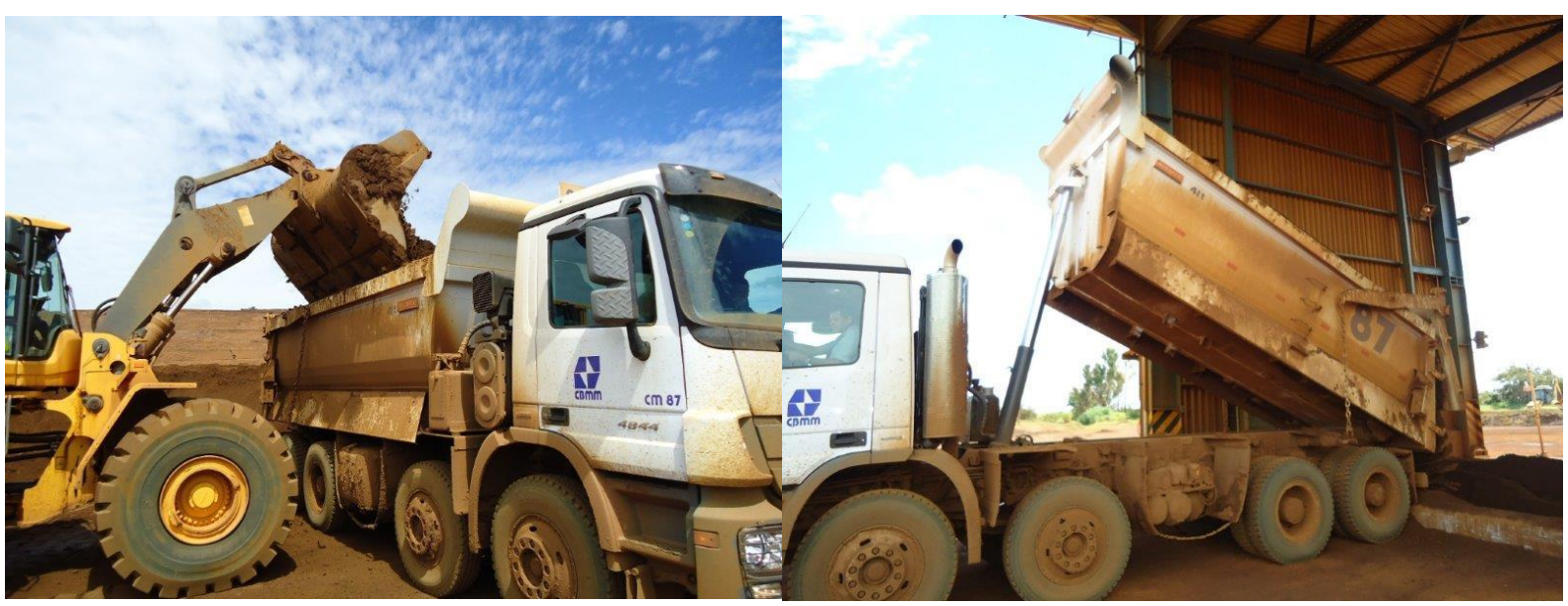

Figura 7- Modelo atual após 12 meses de serviço. Não houve o trincamento dessa estrutura do sobre chassis.

\subsubsection{Comparação dos aços utilizados}

Foram efetuadas micrografias segundo a norma ASTM E3:2011 e ensaios mecânicos nos materiais utilizados nessas caminhões com o objetivo de ter um pleno entendimento das diferenças de desempenho encontrados. A Tabela 3 apresenta os resultados dos ensaios mecânicos, aplicando a norma ASTM A370:2010. Os microligados apresentam maiores valores de limite de escoamento e de limite de resistência. Seu alongamento é inferior ao do aço carbono.

Tabela 3- Propriedades mecânicas obtidas nos aços utilizados nos caminhões basculantes, Aço carbono estrutural padrão ASTM

\begin{tabular}{|l|c|c|c|}
\hline Aço & $\begin{array}{c}\text { LE } \\
(\mathrm{MPa})\end{array}$ & $\begin{array}{c}\text { LR } \\
(\mathrm{MPa})\end{array}$ & $\begin{array}{c}\text { A } \\
(\%)\end{array}$ \\
\hline $\begin{array}{l}\text { Aço } \\
\text { Carbono }\end{array}$ & $260-380$ & $360-510$ & $26-36$ \\
\hline Hardox 450 & 1270 & 1450 & 15 \\
\hline $\begin{array}{l}\text { Domex } \\
700 \mathrm{MC}\end{array}$ & 765 & 810 & 20 \\
\hline
\end{tabular}

\footnotetext{
* Contribuição técnica ao 69 Congresso Anual da ABM - Internacional e ao 14ํㅡㄹ ENEMET - Encontro Nacional de Estudantes de Engenharia Metalúrgica, de Materiais e de Minas, 21 a 25 de julho de 2014, São Paulo, SP, Brasil.
} 
As Figuras 8, 9 e 10 mostram as microestruturas dos materiais empregados. Comparando-se o aço carbono, Figura 8, com o aço microligado aplicado no sobre chassis, Figura 9, verifica-se que o microligado é muito mais fino, com tamanho de grão médio de 3,0 $\mu \mathrm{m}$. No caso do aço carbono, o tamanho de grão médio é de 9,0 $\mu \mathrm{m}$. Ambos são ferríticos, com poucas regiões contendo perlita. O refino da microestrutura é a principal diferença. Já o Hardox 450, Figura 10, apresenta martensita revenida e carbonetos, própria para garantir sua elevada resistência ao desgaste. Esse material também apresenta os maiores valores de limite de escoamento dos materiais testados nesse trabalho, valores acima de $1200 \mathrm{MPa}$.

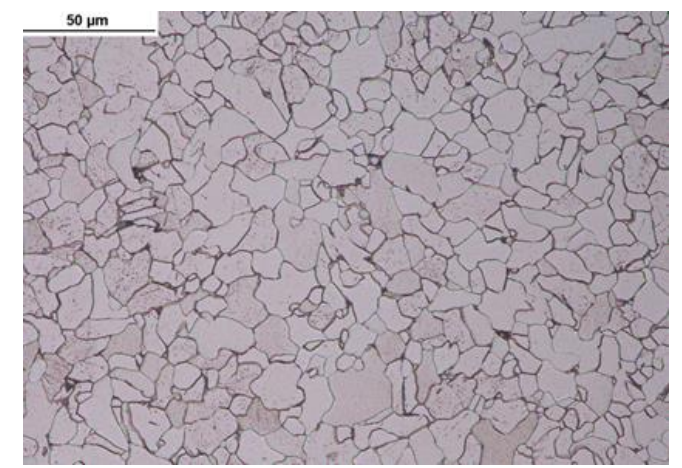

Figura 8 - Microestrutura de chapa de aço carbono. Ferrita com regiões contendo perlita. Tamanho de grão médio de $9,0 \mu \mathrm{m}$.

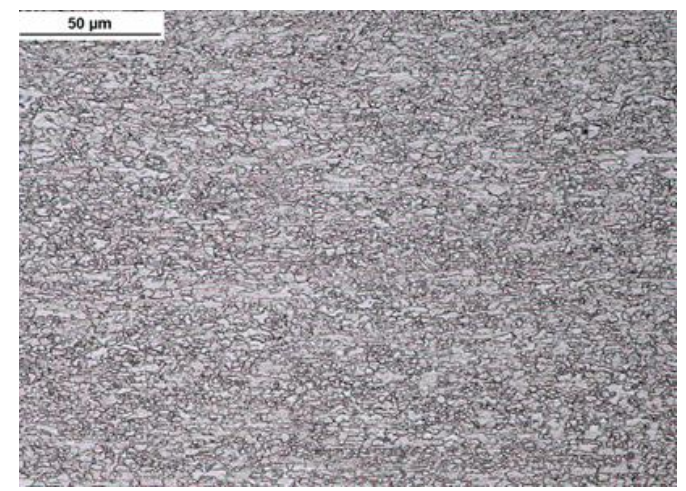

Figura 9 - Microestrutura de aço Domex 700MC. Ferrita com regiões contendo perlita. Tamanho de grão médio de $3,0 \mu \mathrm{m}$.

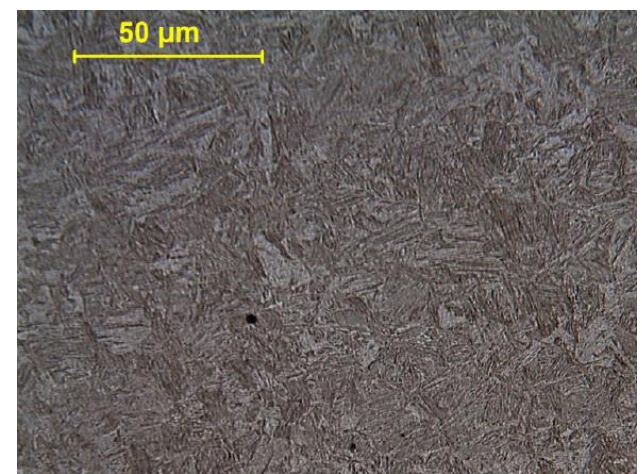

Figura 10 - Microestrutura de aço Hardox 450. Carbonetos finos em matriz de martensita revenida.

\footnotetext{
* Contribuição técnica ao $69^{\circ}$ Congresso Anual da ABM - Internacional e ao 14ํㅡㄹ ENEMET - Encontro Nacional de Estudantes de Engenharia Metalúrgica, de Materiais e de Minas, 21 a 25 de julho de 2014, São Paulo, SP, Brasil.
} 


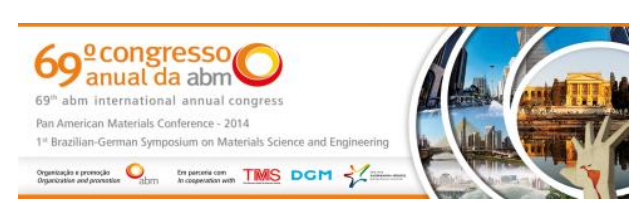

\subsection{Discussão}

A redução de $8,0 \%$ do consumo de combustível foi decorrência, principalmente da redução dos $1.500 \mathrm{~kg}$ da estrutura dos caminhões, o que acaba sendo decisivo quando os caminhões estão trafegando sem carga. Uma vez que os caminhões deixam sua carga e voltam para os locais de abastecimento, trafegam com esse menor peso. Outro fator importante como redutor dos custos de transporte foi a redução dos números de viagens necessárias para transportar o material dentro da Usina de Araxá devido a maior carga transportada por viagem. Reduzir peso e colocar mais carga é a receita inquestionável para o aumento do desempenho e redução dos custos. Fazer isso com a aplicação dos aços microligados ao nióbio, garante uma maior segurança para seu equipamento e para as operações. Não houve o aparecimento de trincas nas estruturas dos sobre chassis. Essas trincas devem ser corrigidas com solda, o que aumenta os tempos de manutenção e a indisponibilidade do equipamento. Além disso, a ausência de trincas coloca a operação sob total controle e previsibilidade, prevenindo-se da ocorrência de qualquer evento imprevisto que venha a colocar o equipamento como indisponível.

As microestruturas dos aços explicam essas diferenças de desempenho. Aumentar a resistência dos aços pode ser feita de várias formas mas com o nióbio, o aumento é proporcionado pelo refino de grão do material, o único mecanismo que aumenta a resistência e a tenacidade do material simultaneamente. Aumentar a resistência mecânica do aço apenas com o aumento do teor de carbono, pode torna-lo mais frágil e com isso, mais sensível a trincamentos. Aumentando o carbono há uma maior tendência ao trincamento na soldagem, conforme mostra o diagrama da Figura 11 [13]. Os materiais com alto carbono não aceitam operações de soldagem tão facilmente quanto os microligados, tornando sua manutenção mais delicada.

A utilização do nióbio nos aços de elevada resistência ao desgaste que são temperados e revenidos, como é o caso do Hardox 450, também tem a função de refinar a microestrutura deixando-a mais tenaz, o que evita que micro trincas decorrentes do desgaste se juntem facilmente e possam abrir trincas maiores com prejuízo para a resistência ao desgaste [14].

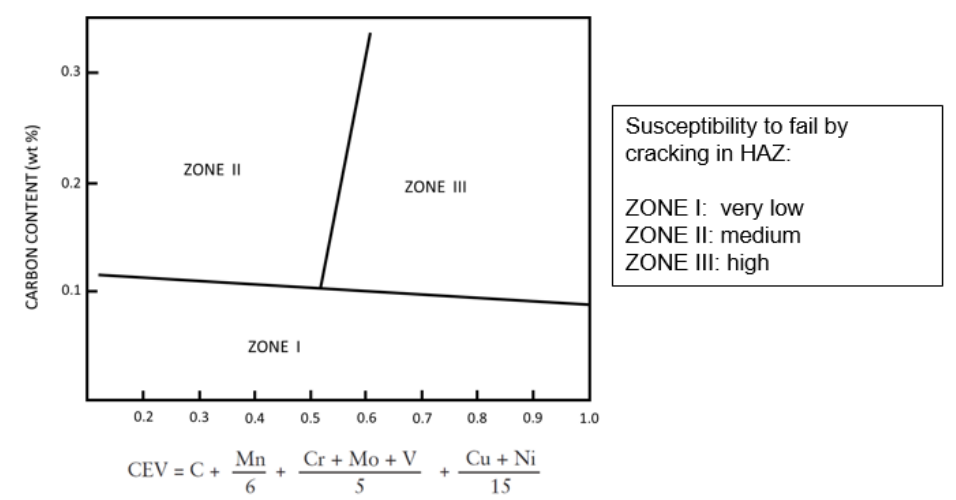

Figura 11 - Diagrama mostrando a susceptibilidade ao trincamento na soldagem em função do teor de carbono e da expressão do carbono equivalente.

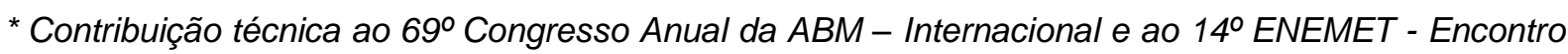
Nacional de Estudantes de Engenharia Metalúrgica, de Materiais e de Minas, 21 a 25 de julho de 2014, São Paulo, SP, Brasil.
} 


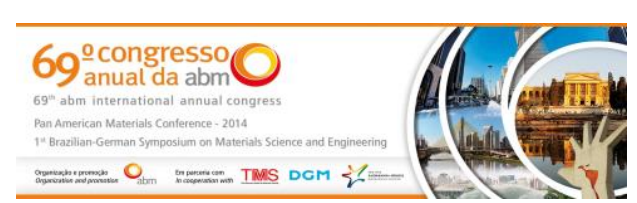

\section{CONCLUSÃO}

Com a utilização de aços de elevada resistência mecânica em vez dos aços carbono em caçambas dos caminhões basculantes que vêm operando nas instalações da CBMM em Araxá foi possível:

- reduzir as massas das caçambas em $25 \%$, viagem,

- aumentar uma média de $1.100 \mathrm{~kg}$ ou $2,7 \%$ de carga transportada por

- reduzir os custos totais de transporte em 3,00\%,

- reduzir o consumo de combustível em $8 \%$.

Os aços microligados ao nióbio, além de maiores resistências mecânicas, têm microestruturas mais finas que os aços carbono. $O$ tamanho de grão médio do microligado foi de 3,0 $\mu \mathrm{m}$ enquanto que o tamanho de grão médio do aço carbono foi de 9,0 $\mu \mathrm{m}$. Não houve trincas por fadiga nos sobre chassis dos caminhões elaborados com o aço microligado ao nióbio durante esses 12 meses de operação.

\section{REFERÊNCIAS}

1 Stuart $\mathrm{H}$. The niobium industry: a commentary, Bulletin Tantalum - Niobium International Study Center, 1986; 85: 1019-2026.

2 Stuart H, Tither G. - The niobium market and the effect of recent innovations in technology - T.I.C. Bulletin, 1983; 74.

3 Araxá Niobium Mine- Mining Magazine, 1982; 146(2).

4 Filho IA, Riffel BF, Sousa CAF. Some aspects of the mineralogy of CBMM Niobium Deposit and Mining and Pyrochlore ore Processing. In: Niobium Science \& Technology, Ed. TMS, Brazil, 2001.

5 Rosa HL, et al - Increasing Transportation Efficiency by Using High Strength Niobium Microalloyed Steel for Truck Dumpers - International Seminar of Application of high strength steels in the lightweight design of commercial vehicles, São Paulo, 2013.

6 Woodhead JH, Keown SR. The history of microalloyed steels, Proceeding of Conference HSLA 85, Peking, ASM, 1986.

7 Mohrbacher $\mathrm{H}$. The relevance of Niobium microalloying in dual phase steels with optimized mechanical properties - Presented at BAO 2010, Shanghai, China.

8 Olsoon K, Gladh M, Hedin JE, Larsoon J. Niobium Microalloyed Sheet Steels For Automotive Applications - microalloyed high strength steels for reduced weight and improved crash performance in automotive applications- TMS (The Minerals, Metals \& Materials Society), 2006

9 Bhattacharya D. Role of Niobium in Advanced High Strength Steels for Automotive Applications- International Conference on High Strength Low Alloy Steels, HSLA Steels, Beijing, China, 2011.

10 Hebesberger T, Pichler A, Pauli H, Ritsche S. Dual Phase and complex phase steels, AHSS material for a wide range of applications- Voestalpine, Linz, Austria - 2nd International Conference on Steels in Cars and Trucks - SCT 2008, Wiesbaden, Germany, 1-5 june 2008.

11 Sugimoto K, et al. Application of niobium to automotive ultra-high strength TRIP aided steels with bainite - ferrite and / or martensite matrix- Materials Science and Technology, 2007.

12 Bian J. - Press hardening - the lightweight technology for making cars with more safety and less CO2 emission, APAC Seminar, India , 2011.

13 Graville BA. Cold cracking in welds in HSLA steels. Proc. Int. Conf. American Society for Metals, Nov. 1976.

14 Hulka K, Kern A, Schriever U. Application of niobium in quenched and tempered high strength steels, Materials Science Forum, 2005; 500- 501.

\footnotetext{
* Contribuição técnica ao $69^{\circ}$ Congresso Anual da ABM - Internacional e ao 14ํㅡㄹ ENEMET - Encontro Nacional de Estudantes de Engenharia Metalúrgica, de Materiais e de Minas, 21 a 25 de julho de 2014, São Paulo, SP, Brasil.
} 